\title{
QR Code como incremento ao turismo cultural do barroco centro histórico de São Francisco do Sul, SC
}

\author{
QR Code as an increase to the cultural tourism of barroco historical center of \\ São Francisco do Sul, SC
}

\author{
QR Code como mejorar el turismo cultural del barroco centro histórico del San \\ Francisco del Sur, SC
}

Diva de Mello Rossini ${ }^{1}$

Carlos Alberto Tomelin ${ }^{1}$

Luciano Torres Tricarico ${ }^{1}$

Gabriela Mocellin ${ }^{1}$

\begin{abstract}
Resumo: Os preceitos da investigação qualitativa nortearam esta pesquisa, que foi realizada por meio de incursões investigativas em fontes bibliográficas, documentais e de campo. O objetivo foi a elaboração de um roteiro turístico cultural para o centro histórico de São Francisco do Sul, SC. O contéudo foi descrito por meio de um texto que pode vir a ser convertido para um código bidimensional (QR Code), a ser afixado em totens, para que estes esteja aptos a fornecer informações sobre a história da formação dessa cidade para os residentes, turistas brasileiros e estrangeiros e também aos portadores de necessidades especiais, promovendo assim, a socialização desses conhecimentos para todos.
\end{abstract}

Palavras-chave: Roteiro turístico; QR Code; centro histórico; turistas.

Abstract: The precepts of qualitative research guided this research, which was carried out through investigative incursions into bibliographical, documentary and field sources. The objective was the elaboration of a cultural touristic route to the historic center of São Francisco do Sul, SC. The content was described by means of a text that can be converted into a two-dimensional code ( $Q R$ Code), to be displayed in totems, so that they are able to provide information about the history of the formation of this city for residents, Brazilian tourists and foreigners and also to those with special needs, thus promoting the socialization of this knowledge for all. Keywords: Touristic route; QR Code; historic center; tourists.

Resumen: Los preceptos de la investigación cualitativa guiaron esta investigación, que fue realizada por medio de incursiones investigativas en fuentes bibliográficas, documentales y de campo. El objetivo fue la elaboración de un itinerario turístico cultural para el centro histórico de San Francisco del Sur, SC. El contenido se describe por medio de un texto que puede convertirse en un código bidimensional (QR Code), que se colocará en totems, para que éstos puedan proporcionar información sobre la historia de la formación de esta ciudad para los residentes, los turistas brasileños y extranjeros y también a los portadores de necesidades especiales, promoviendo así la socialización de estos conocimientos para todos.

Palabras clave: Itinerario turístico; Código QR; centro histórico; turistas.

\section{INTRODUÇÃO}

Este artigo constitui a etapa final do projeto de pesquisa aprovado pelo Conselho Nacional de Desenvolvimento Científico e Tecnológico, Chamada Universal - MCTI/CNPq n. 14/2013, quando foi estudada a possibilidade da aplicação do QR Code como mais um instrumento que poderá contribuir com a disseminação das informações sobre o patrimônio material do centro histórico com o desenvolvimento do turismo cultural na cidade de São Francisco do Sul, SC, objeto empírico. Esta é a terceira cidade mais antiga do Brasil, dotada de um rico patrimônio urbano arquitetônico, modelo de cidade construída sob os preceitos portugueses pombalinos

\footnotetext{
${ }^{1}$ Universidade do Vale do Itajaí, Itajaí, Santa Catarina, Brasil.
} 
do século XVIII, sítio onde pode, ser observadas várias camadas, as quais registram as mudanças que ocorreram ao longo do tempo na estrutura social e econômica dessa comunidade.

Vale ressaltar que poucos são os incentivos locais, as políticas públicas ou as iniciativas da sociedade organizada, em prol da preservação da história edificada e da divulgação de suas riquezas, pois se restringem àquelas realizadas pelo escritório local do Instituto do Patrimônio Histórico e Artístico Nacional. A administração pública municipal compreende que as potencialidades turísticas estão nas praias locais e do entorno, relegando para segundo plano o turismo cultural.

Acredita-se que essa falta de compreensão sobre a relevância do patrimônio histórico esteja relacionada ao pouco tempo que as políticas preservacionistas passaram a vigorar no país, no Brasil, pois as ações do Serviço do Patrimônio Histórico e Artístico Nacional (SPHAN) somente se intensificaram a partir das décadas de 1980 e 1990, quando iniciaram as aplicações das políticas patrimoniais, a partir do apoio da elite cultural. Este, o momento em que os governos estaduais e municipais sentem-se estimulados a preservar os centros urbanos, reconhecendo-os como elementos essenciais para a vida da sociedade (ENDRES; OLIVEIRA; MENEZES, 2007 ).

Essas mudanças que houve no contexto social e político do país permitiram que os centros urbanos fossem revitalizados e passassem a serem entendidos como lugares dinâmicos da vida urbana, animados pelo fluxo de pessoas, veículos e mercadorias, espaços que historicamente foram eleitos para sediar instituições públicas e religiosas. Assim, associadas ao desenvolvimento tecnológico e à globalização, fizeram com que os núcleos históricos deixassem de ser o "lócus" da produção para se tornar objeto de consumo, oportunizando aos meios de comunicação e marketing que instaurassem uma verdadeira competição entre lugares, onde a paisagem cultural das cidades tornou-se um produto cobiçado por investidores, políticos, moradores e turistas (VARGAS; CASTILHO, 2009).

O uso do Código de Resposta Rápida (QR Code) como uma ferramenta que socializa as informações turísticas para portadores de necessidades especiais e turistas estrangeiros é uma forma de se apropriar de tecnologias já existentes para usos diversificados, atribuindo a gestão das atividades turísticas um caráter inovador (OKADA; SOUZA, 2011).

O método aplicado foi investigativo, realizado em fontes bibliográficas, documentais e de campo. Os resultados alcançados foram analisados qualitativamente e comparados com o referencial teórico estudado.

Ao término da pesquisa foi elaborado um roteiro turístico cultural, para ser percorrido a pé, junto à paisagem edificada e natural, a qual possibilita que o turista vivencie a história da formação dessa cidade. A sequência do trajeto foi demarcada com números, no mapa da cidade e também elaborado um material para ser convertido em QR Code e instalado em totens para informações turísticas em pontos estratégico desse roteiro.

\section{QR CODE}

Os códigos de Resposta Rápida (QR Code) surgiram na década de 1994, foram desenvolvidos pela empresa japonesa Denso-Ware, uma empresa do grupo Toyota. Seu objetivo era facilitar a identificação das partes dos carros nas fábricas e também o processo logístico em todo o mundo. Ele resulta de uma evolução dos códigos de barra tradicionais e são capazes de armazenar até 100 vezes mais dados e caracteres do que os tradicionais códigos de barras (KARASINSKI, 2013). 
O QR Code armazena diversas informações sob a forma de links, sites, números de telefone e textos. As informações são guardadas quer na vertical, quer na horizontal e podem ser lidas a partir de qualquer direção.

Segundo dados do Interactive Advertising Bureau Brasil (IAB Brasil, 2016 ), o ano de 2010 foi o da consolidação das redes sociais, do e-commerce, dos aplicativos para equipamentos móveis e também da ascensão dos sites de compras.

Alguns autores consideram o uso de códigos de barra 2D como uma ferramenta de apoio a deficientes visuais, pois atuam na identificação de objetos por meio de tal código (EBRAHIM et al., 2005 ). Para sanar a dificuldade de enquadramento do código, Xue et al. (2010) sugerem que seja utilizado um detector capaz de reduzir os efeitos da variação de luz, de rotação e de distorção perspectiva.

O QRcode é um código matricial composto por um padrão de barras bidimensionais que se tornou referência no uso comercial atual, seu uso mais comum é a codificação de apontadores que são lidos por uma câmera a qual estabelece uma conexão entre objetos do mundo físico com conteúdos na internet. Possui uma alta capacidade de armazenamento e uma rica especificação nesse padrão de código de barras. A estrutura do código QR contempla além dos dados de versão e correção de erros, elementos estruturais, como: margem silenciosa no entorno do código de barras para facilitar a detecção do símbolo, com no mínimo 4 módulos de largura, cada módulo corresponde à menor unidade de informação no código (o menor quadrado preto ou branco); padrões de alinhamento para corrigir distorções não lineares ao longo da área do símbolo; padrão de sincronização que indica a localização das linhas e colunas dos módulos no símbolo; e os padrões de posição, utilizados para auxiliar na localização do símbolo, projetadas para serem encontrados em qualquer direção uma vez que a proporção de alternância entre pixels brancos e pretos (razão de 1:1:1:3:1:1:1) se mantém constante ao longo das linhas de escaneamento que passem através de seu centro (BELUSSI, 2012).

Esses códigos são compostos por imagens digitais com um número finito de elementos, os pixels. Atualmente poucas áreas técnicas não se apropriam de alguma forma de processamento digital de imagens, cuja principal fonte de energia é a eletromagnética, mas também incluem a acústica e eletrônica, são geradas pela combinação de uma fonte de iluminação direta ou reflexão e são captadas mediante sensores digitais que captam a luminosidade das imagens projetadas continuamente. Para criar uma imagem digital, é preciso converter os dados do sensoriamento contínuo em formato digital, isto envolve os processos de amostragem e quantização, transformando as imagens em coordenadas e assim convertendo-a em formato digital e armazenamentos. Já a decodificação é o processo inverso ao da codificação (MELGAR, 2013 ).

Os códigos corretores de erro para a leitura dos QR code são utilizados em múltiplos sistemas de comunicação, como: equipamentos de armazenagem de informações digitais como CD, DVD, Barcodes e QR codes; comunicação sem fio incluindo telefones móveis e links micro-ondas; comunicação satelital; televisão digital e comunicação entre modens ADSL x ADSL, dentre outros (MELGAR, 2013).

Esses avanços tecnológicos que vêm ocorrendo na área móvel possibilitaram novas formas de comunicação para o mobile marketing, o que, segundo Kotler e Keller (2006), caracteriza-se pelas ações desenvolvidas com telefone celular, geralmente utilizado para elevar a construção de um relacionamento satisfatório e duradouro entre as empresas e clientes. Essa nova ferramenta de marketing também pode ser utilizada para o avanço da socialização de conhecimentos 
relativos à memória e a identidade de uma sociedade. Essa ferramenta pode ser incorporada no arsenal de equipamentos utilizados para apoio ao turismo.

A leitura das informações armazenadas em um QR Code pode ser feita a partir de qualquer smartphone com câmera. Também é necessário um software leitor de QR Code e, eventualmente, acesso à internet, no caso de o código ser um endereço eletrônico em vez de um simples texto. Utilizando essas ferramentas, basta posicionar o código à frente da câmera, e o software realiza a detecção do QR Code, retornando a informação codificada, em forma de texto, imagem, ou URL (SASSAKI, 1997).

Optou-se pelo uso do QR Code pelo fato de este apresentar inúmeras vantagens em relação a outros métodos de codificação de barras. Em primeiro lugar, por conter informações nas direções verticais e horizontais, comporta uma quantidade considerável de informação a mais que os tradicionais códigos de barra de uma dimensão. Além disso, em relação ao espaço ocupado, o QR Code ocupa aproximadamente um décimo da área de um código de barras padrão de uma dimensão (DENSO-WAVE, 2012 ).

\section{CIDADE COMO CULTURA MATERIAL}

O Instituto Nacional do Patrimônio Histórico e Artístico Nacional intitula de Cultura Material, um conjunto de bens culturais, classificado de acordo com a sua natureza, seja ela histórica, de belas artes, de artes aplicadas, arqueológica, paisagística e etnográfica. Essa classificação os divide em bens imóveis, como os núcleos urbanos, sítios arqueológicos e paisagísticos; e bens móveis individuais, como coleções arqueológicas, acervos museológicos, documentais, bibliográficos, arquivísticos, videográficos e cinematográficos (BRASIL, 2011).

Portanto a modernização, globalização, gerou a estandardização e a homogeneidade das cidades; portanto a diferenciação através da original identidade local é um trunfo, pois é através da cultura local que as cidades poderão se individualizar, acentuando suas identidades, marcando seu lugar no panorama mundial. A economia cultural que envolve essas cidades originais repletas de aspectos diferentes e entrelaçados as destaca frente à indústria cultural, à indústria do turismo e à economia simbólica.

Essa nova economia que deixou de ser informacional para se tornar cultural, cria um novo cenário no qual a cultura é a mola propulsora do seu desenvolvimento e as exigências voltam-se para a revitalização da urbe, ela é o instrumento de desenvolvimento econômico. A originalidade dos espaços torna-se um diferencial para disputa entre as cidades, ou seja, aquela que apresentar melhores condições do patrimônio cultural irá atrair capitais, investimentos, empresas, moradores e turistas (ARANTES, 1998; HALL, 2001).

A busca por renovação urbana privilegia zonas como centros históricos, áreas centrais degradadas e vazios urbanos, resultantes do processo de desindustrialização- antigas zonas portuárias, ferroviárias e industriais. Essas transformações urbanas buscam reverter os efeitos danosos das mudanças econômicas pós-fordistas e adequar o ambiente construído à nova economia. As novas áreas de intervenção devem oferecer condições para a produção e o consumo da cultura e para o turismo de uma maneira geral. As transformações espaciais não são consideradas somente na sua dimensão físico-territorial, mas envolvem, em grau crescente, ponderações de ordem simbólica. O lugar, a imagem e a identidade, passam a ser elementos da cultura local e se tornam peças fundamentais para a operacionalização dessas mudanças (VAZ, 2004). 
Vale ressaltar que as cidades históricas preservadas e revitalizadas precisam velar pelo seu futuro, para não correrem o risco de serem degradadas e destruídas pelo abandono e descaso das políticas públicas de restauro e preservação, ou pelos fluxos de um turismo devorador e destruidor, incapaz de respeitar o patrimônio histórico. As cidades que descobriram seus "tesouros" arquitetônicos e urbanísticos precisam tomar a palavra "revitalização" muito a sério. Isso não significa transformar edifícios históricos em museu, mas usá-lo mantendo a sua função original com todas as sofisticações do passado. E, também, nada impede que edifícios e tradições que resistiram ao tempo se voltem para o futuro, assumindo novas funções e embelezando as cidades, contribuindo para a valorização do patrimônio e o desenvolvimento do turismo cultural, sem deixar de lado as características do espaço e as necessidades da população receptora sob os quais recaem os impactos positivos e negativos da atividade turística (FREITAG, 2003).

\section{O CENTRO HISTÓRICO DE SÃO FRANCISCO DO SUL}

Esta investigação parte do pressuposto de que a vida urbana nessa localidade iniciou com a ocupação portuguesa no século XVII (SANTOS; NACKE; REIS, 2004 ) e são os registros dessa época e os posteriores a ela, que serão apontados durante a realização da pesquisa de campo.

Este território foi colonizado pelas bandeiras paulistas de colonização, no ano de 1671 (PEREIRA, 2004 ). No ano de 1665 passou de Vila para Paróquia Nossa Senhora da Graça e, em 15 de abril de 1847, foi elevada à categoria de cidade (PREFEITURA MUNICIPAL DE SÃO FRANCISCO DO SUL, 2013 ).

Para compreender a morfologia urbana, é primordial conhecer o ponto de partida das cidades, se não soubermos onde estivemos, não saberemos aonde vamos (ROSSI, 1995).

São Francisco do Sul, apesar de ter sido colonizado pelos vicentistas, tem a sua história vinculada à Baia da Babitonga, local que a conecta com o período das navegações portuguesas a partir do século XVI, e atualmente com o transporte de cargas nacionais e internacionais que acontecem pelo porto, principal atividade econômica.

Implantado sobre uma pequena elevação, o centro histórico, expressa as características dos territórios ocupados pelos povos da antiguidade clássica. O arruamento se apresenta sob a forma de uma malha reticular, embora o traçado não seja ortogonal, devido a topografia ser acidentada, assemelha-se à malha urbana de Lisboa do período das intervenções pombalinas. A ocupação desse território segue os preceitos das Cartas Régias dos séculos XV, XVII e XVIII, as quais ditam que o plano de ocupação deve adaptar-se às características morfológicas do terreno. Esse fato confere ao sítio físico uma ambiência de forte centralidade em relação ao núcleo urbano que ainda se faz presente (AUGUSTO-FRANÇA, 2009).

Vale ressaltar que, no século XVIII, as cidades eram construídas a partir de planos regulares, concebidos segundo traçados geométricos, planejadas racionalmente na sua estrutura global. A praça era o elemento central, sendo que os conceitos de planejamento e de beleza urbana estavam associados à simetria do traçado e à adaptação a modelos arquitetônicos uniformes, na maior parte das vezes, era onde se localizava o pelourinho, local onde também deveria ser edificada a igreja e a casa de Câmara e Cadeia (PEREIRA, 2004).

Em São Francisco do Sul (BR), os desenhos das ruas principais estão orientados paralelos à linha de costa e as secundárias cruzando-as, quase sempre, em ângulo reto. As ruas definem um conjunto de quarteirões retangulares orientados na direção do mar. Cada um desses quarteirões 
é constituído por duas filas de lotes urbanos organizados costas-com-costas. As frentes desses lotes estão voltadas para as ruas principais, todos os lotes são retangulares. Junto ao centro, essa a igreja, situada no meio de uma praça retangular, a qual corresponde pelas suas dimensões e pela sua relação com a restante malha urbana, a um quarteirão não construído. Esse plano expressa a manifestação dos princípios barrocos sobre o planejamento medieval, modelo que foi aplicado em Portugal, no Brasil e no Oriente, figura 01 (OLIVEIRA, 2002).

Figura 1 - Mapa da Cidade de São Francisco do Sul (BR)

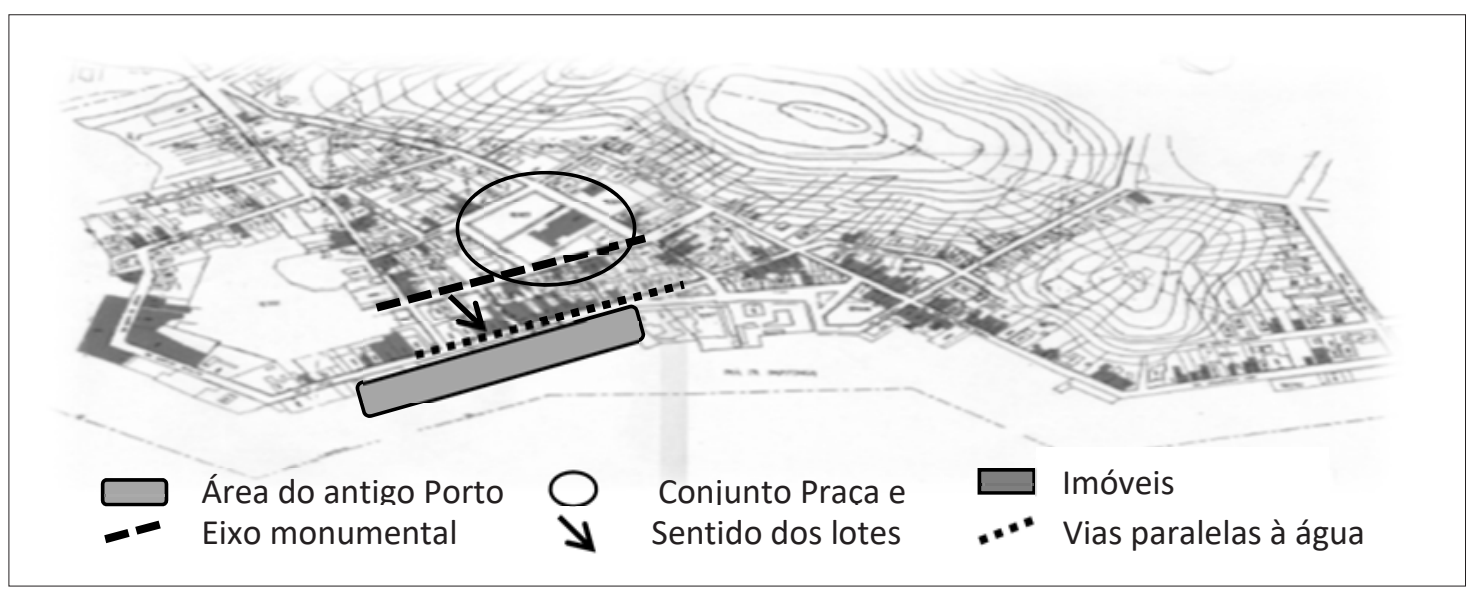

Fonte: PREFEITURA MUNICIPAL DE SÃO FRANCISCO DO SUL, 2013. Informações adicionadas pelos autores, 2014.

As áreas selecionadas para o roteiro foram aquelas que possuem uma maior concentração de edificações cujas fachadas são protegidas por legislação federal (IPHAN, 2010).

Sendo assim, a sequência do roteiro é identificada por ordem numérica, o número 1 indica o início e término do roteiro, junto ao Mercado Público. Os quadros pontilhados apontam as áreas que concentram as edificações de maior relevância histórica, figura 2.

Figura 2 - Roteiro com os trajetos da pesquisa de campo, numerados de acordo com a sequência do percurso e a relevância histórica.

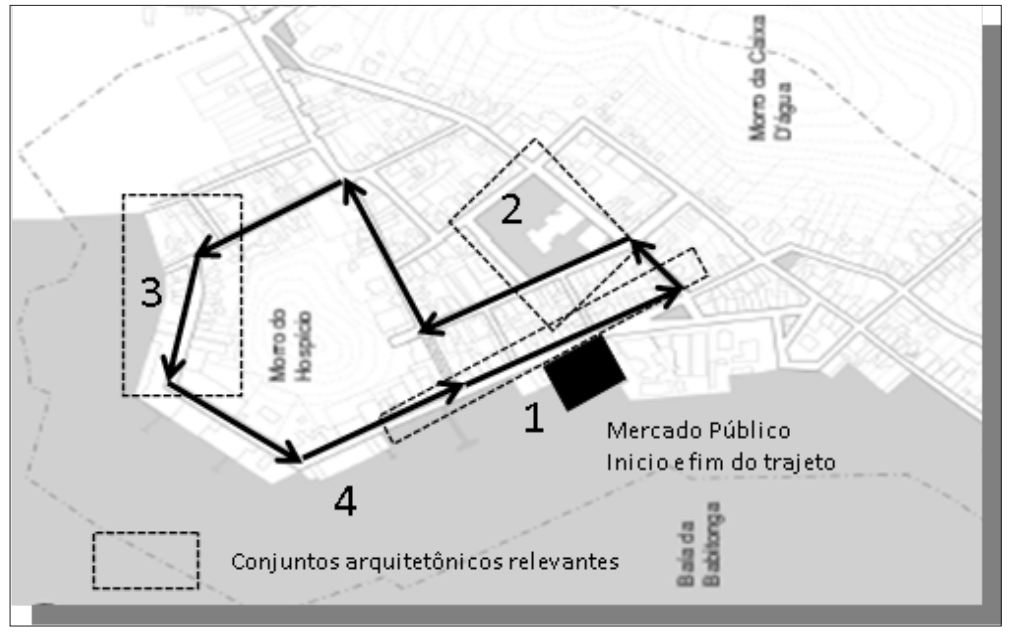

Fonte: Acervo do ETEC SFS IPHAN, 2010. Informações adicionadas pelo autor, 2014. 
O Mercado Público, edifício construído no ano de 1900 (IPHAN, 2010). É um edifício que contrasta na paisagem, caracteriza-se como uma iniciativa local que aponta uma sucessão de pontos de vista. As aberturas dessa construção são ricas em pormenores, com detalhes em ferro e cimalhas de argamassa, propiciam a vista do exterior para o interior. Esse edifício reduz a magnitude de sua paisagem, perspectiva velada, quando volta as costas para a Baia de Babitonga. Já junto a Baia, a perspectiva é grandiosa, apesar de ser um dos limites físicos dessa área. Sendo assim o traçado urbano inicial parte da área do antigo porto e a conecta com a parte alta da cidade, figura 3.

Figura 3 - Mercado Público, vista externa e vista de dentro para fora

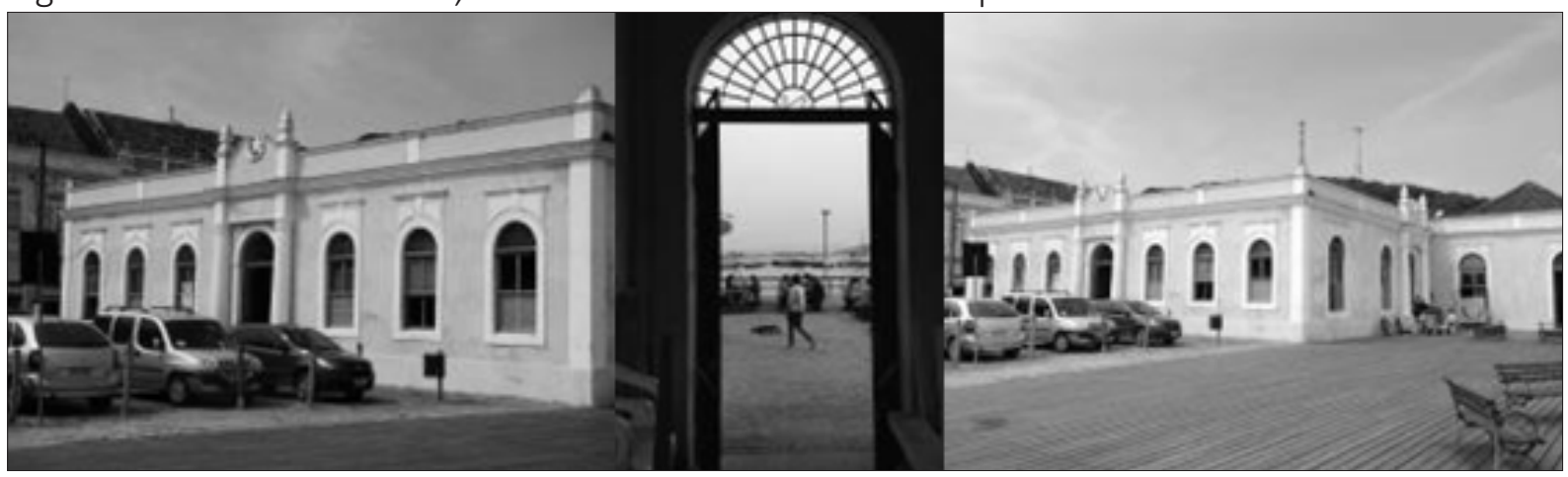

Fonte: Acervo do autor, 2013.

Na sequência, identifica-se a complexidade de edificações históricas, primeiro individualmente, depois em conjunto, figura 4. Observa-se que, nos dois lados da via, há edificações de valor histórico, fazendo com que a paisagem desse entorno seja composta por um conjunto urbano em estilo eclético, que data do fim do século XIX, início do século XX. Algumas casas ocupam toda fachada do lote, estão construídas sobre o alinhamento da via pública e sobre os limites laterais do terreno. Essa tipologia de ocupação dos lotes em fita data do período colonial, e os edifícios são de arquitetura eclética, estilo arquitetônico típico do início do século XIX (REIS FILHO, 1970).

Figura 4 - Conjunto de edifícios que compõe o lado oposto a Baía de Babitonga.

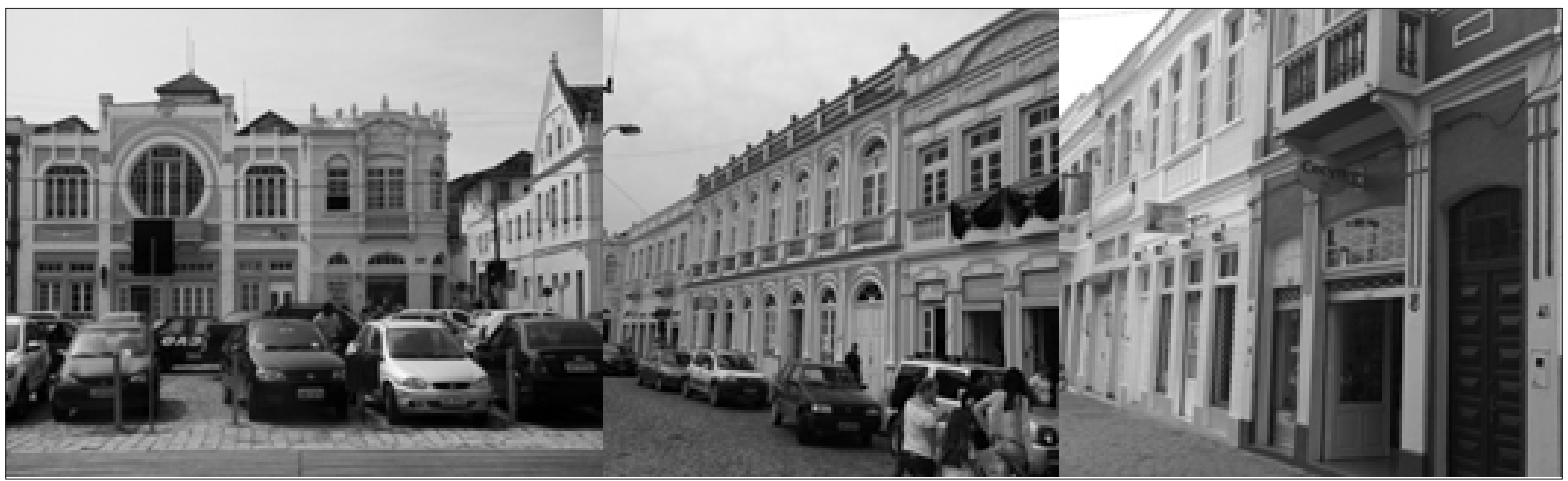

Fonte: Acervo do autor, 2013.

Continuando o percurso, surge uma via não reticular típica do período colonial, na qual a sensação é de que se perde a noção do todo e observam-se as partes, figura 5. Surgem elementos que criam um efeito de silhueta, conteúdo e local. Contrastando com essa paisagem, está um 
edifício, posto de gasolina, de tipologia arquitetônica racionalista típica do início do modernismo no Brasil (REIS FILHO, 1970).

Figura 5 - Conjunto de edifícios que compõe o lado oposto a Baía de Babitonga

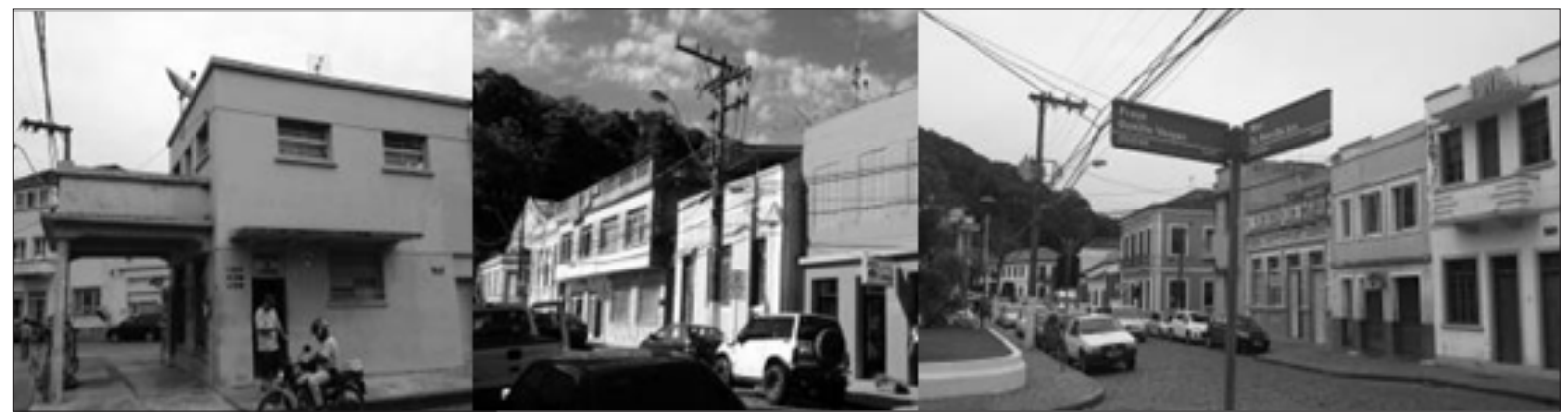

Fonte: Acervo do autor, 2013.

Ao ingressar no trajeto 2, surge um aclive que culmina com a vista de uma edificação monumental, edifício com uma arquitetura repleta de ornamentos, com aberturas em arco abatido, cimalhas e guarda-corpo de ferro, com uma marcação entre os dois pavimentos, semelhante às tipologias de edificações descritas na regulamentação da cidade pombalina de Lisboa (PT). À medida que a inclinação aumenta, a rua se fecha, cria uma perspectiva velada, figura 6.

Figura 6 - Vista do conjunto de edifícios que compõe o aclive do trajeto 2

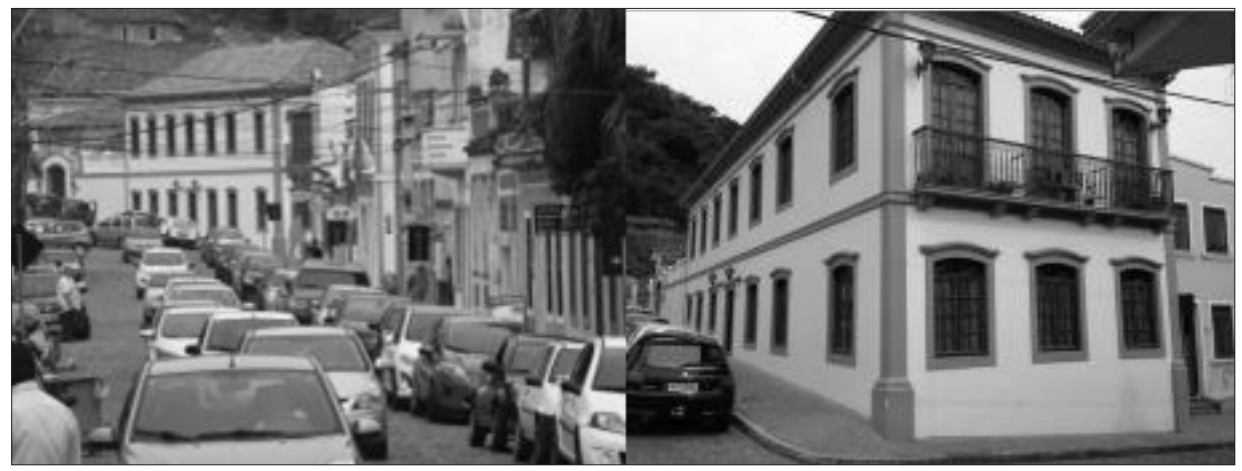

Fonte: Acervo do autor, 2013.

Ao dobrar a esquina, aparece o campanário da Igreja Nossa Senhora das Graças, edifício cuja morfologia Ihe confere monumentalidade, como uma escultura. Sua construção iniciou em 1699, com argamassa composta de cal de concha, areia e óleo de baleia, originalmente construída em estilo veneziano e com uma só torre, no entanto passou por diversas modificações e, em 1921, foi construída a segunda torre, figura 10 (IPHAN, 2010).

Em 1808, na parte interna da Igreja, foi colocado forro de madeira, cuja pintura foi realizada em 1821, logo depois veio o órgão, foi concluída em 1830. A primeira grande reforma ocorreu em 1926, com a restauração da fachada e abertura de diversas janelas, colocação de cimalhas e afrescos. A última reforma ocorreu em 1945. Em 1949 foi restaurado o altar-mor e construída a segunda torre (IPHAN, 2010). 
Junto ao largo da Igreja, está a Praça Getúlio Vargas, cujo tipo de implantação segue os moldes das cartas régias portuguesas do período barroco, há uma massa de vegetação que individualiza a paisagem, promove o contraste entre os dois lados da via, um fechado e o outro repleto de edificações construídas ao rés-do-chão, ocupando todo o lote, sendo uma implantada junto à parede limite da outra, figura 7 (AUGUSTO-FRANÇA, 2009).

Figura 7 - Conjunto de edifícios composto pela igreja, praça e o Cine $X$

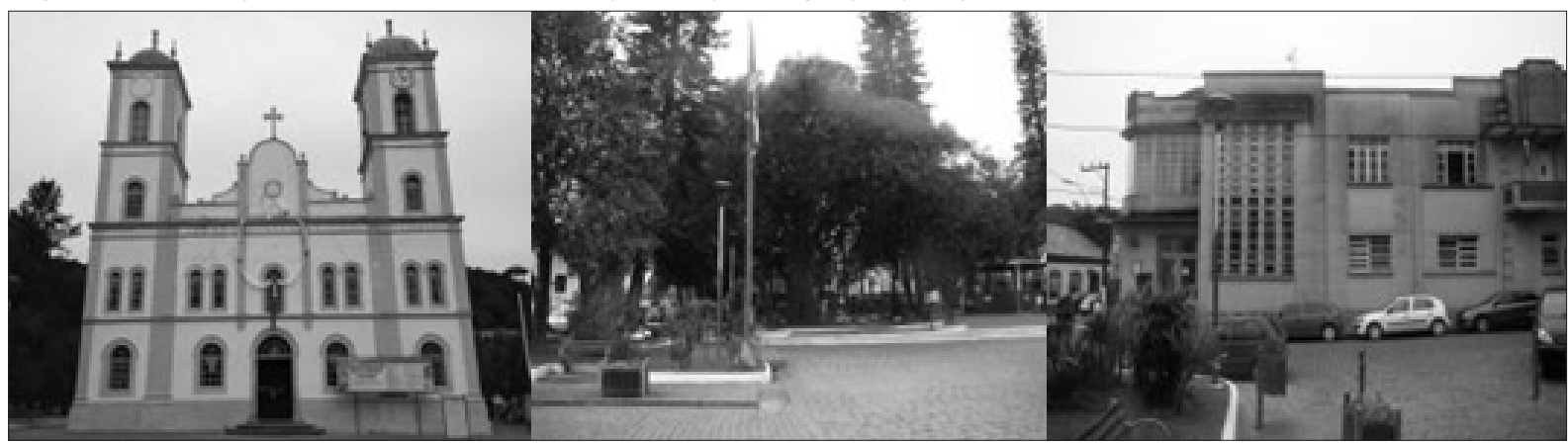

Fonte: Acervo do autor, 2013.

Os edifícios da figura 8 foram construídos ao rés-do-chão, possuem tipologia arquitetônica típica do período colonial, com um acesso principal e duas janelas e ocupação total do lote, em fita (REIS FILHO, 1970).

Figura 8 - Conjunto de edifícios residenciais e comerciais que compõe o lado oposto ao igreja.

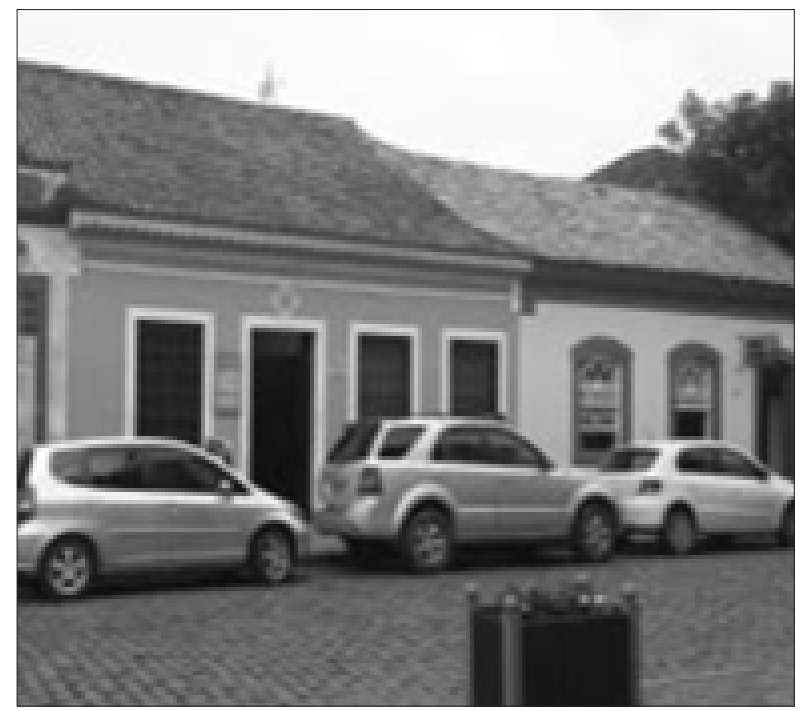

Fonte: Acervo do autor, 2013

O trajeto 4, leva ao Museu do Mar, figura 9, antigo armazém, primeiro do gênero no Brasil, foi instalado em setembro de 1991 e inaugurado em dezembro de 1992. O local abrigava anteriormente o conjunto de depósitos e escritórios da antiga Empresa de Navegação Hoepke, construídos no fim do século XVIII. Edifício de arquitetura eclética, ele tem influência alemã, com impressionante estrutura de madeira (IPHAN, 2010). 
Figura 9 - Trajeto 4, Museu do Mar

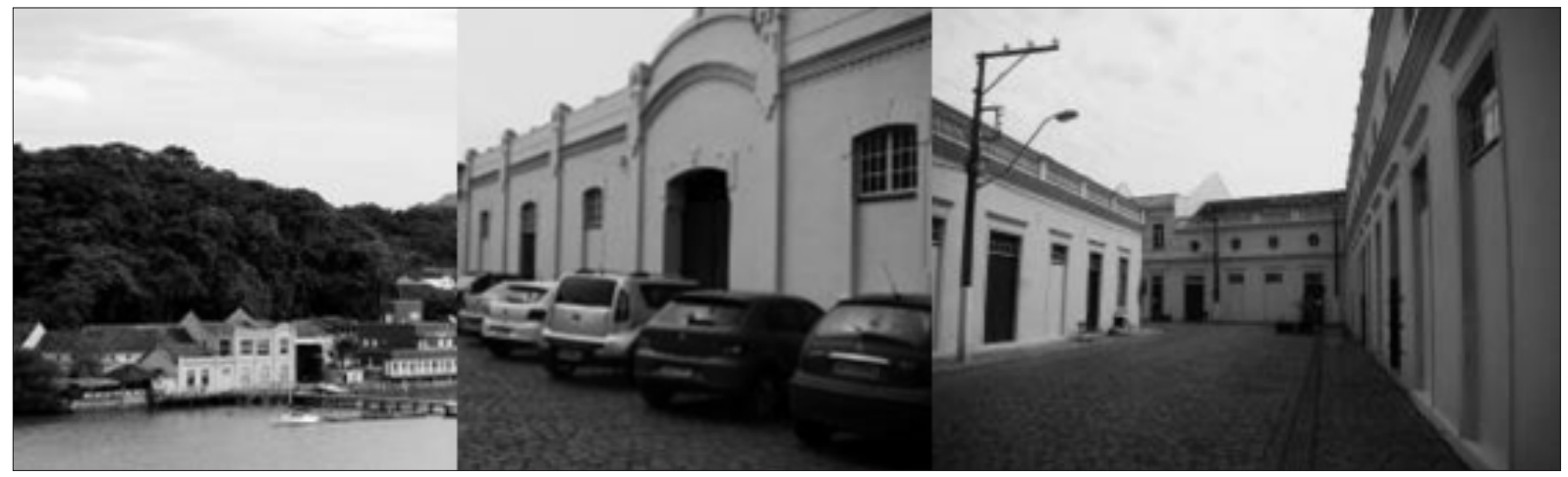

Fonte: Acervo do autor, 2013.

Fechando o roteiro, no lado oposto à baía, limite, forma-se um conjunto de edifícios, algumas imagens repetem as informações do início do trajeto, quando se justapõem. O edifício que se destaca é o do antigo Clube XXIV de Janeiro, construído em 1905 defronte à Baía de Babitonga, cuja arquitetura conserva fortes traços do estilo do período colonial. O intuito do projeto, elaborado por Marcos Gorresen e José Augusto Nóbrega, era que os ambientes fossem requintados para atender as atividades culturais e sociais. Sofreu reformas para abrigar o Cine Radium em 1950. Dos traços originais da edificação - arquitetura em estilo eclético- pouco resta além da fachada principal e as paredes periféricas. No pavimento térreo, atualmente, estão algumas lojas e, no segundo pavimento, há um grande salão. O Clube XXIV de Janeiro, após muitos anos de desgaste, foi restaurado através do Projeto Monumenta e, segundo informações do Ministério do Turismo, será transformado em um centro de eventos, figura 10 (IPHAN, 2010).

Figura 10 - Fechamento do roteiro, Clube XXIV de Janeiro e o conjunto de edifícios, implantados na margem oposta à Baia de Babitonga

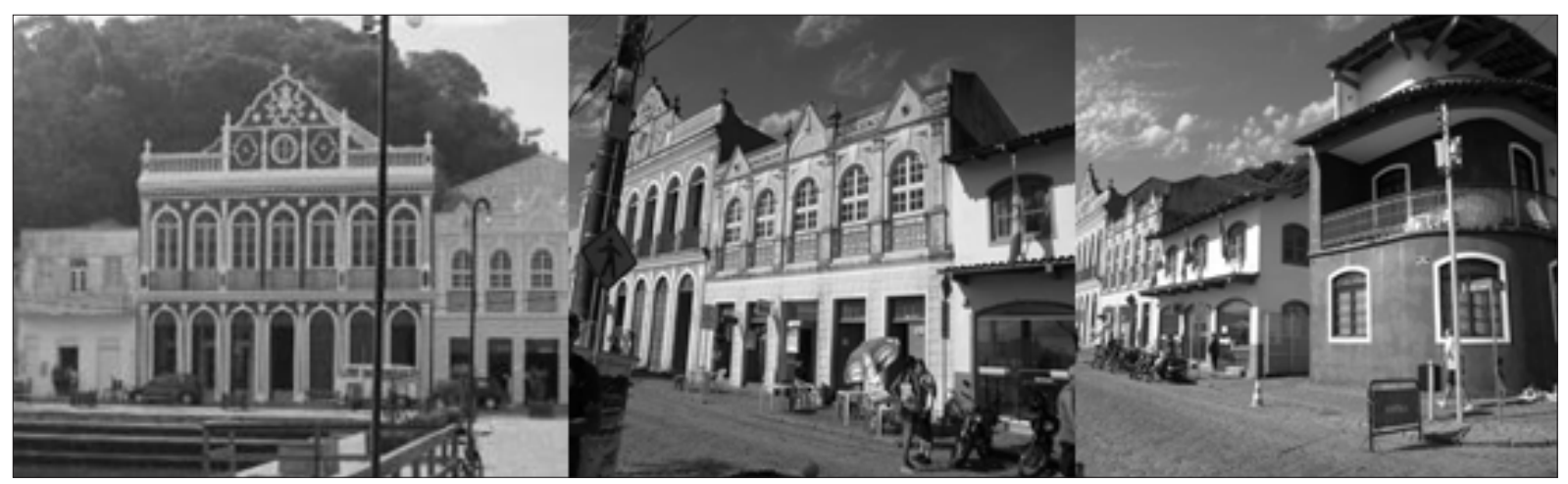

Fonte: Acervo do autor, 2013.

Os traçados e edificações foram descritos a partir do conteúdo disponível em publicações e por meio dos registros fotográficos realizados pelo pesquisador in loco.

As imagens foram comparadas à da bibliografia, e os estilos arquitetônicos descritos detaIhadamente, com uma linguagem comum, para que o entendimento seja universal. Essas informações necessitam passar pelo processo de codificação bidimensional, para que posteriormente possam ser afixadas nos totens. A locação dos totens, na figura 11, foi norteada pelo princípio de encaminhamento do transeunte pelo circuito. 
Figura 11 - Mapa com a localização dos totens munidos de informações codificadas.

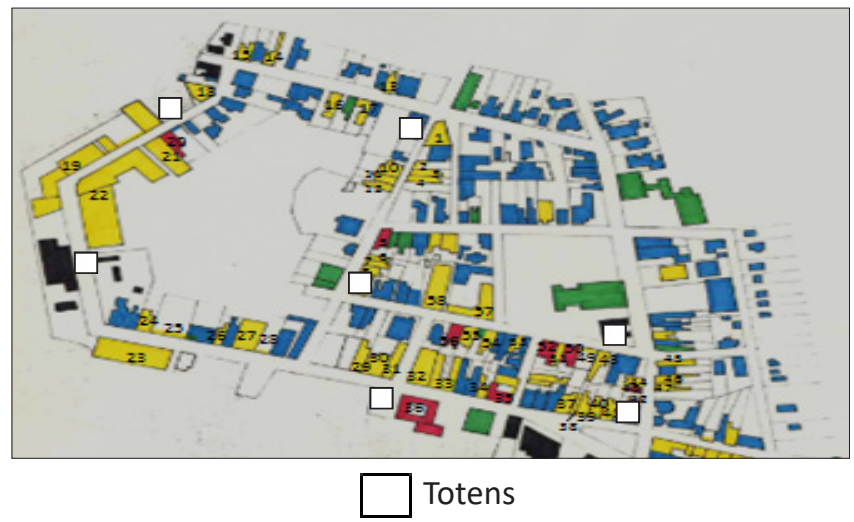

Fonte: IPHAN, 2010. Informações adicionadas pelo autor, 2016.

\section{CONSIDERAÇÕES FINAIS}

Esta investigação demonstra a presença de traços, dispostos em layers, dos planos portugueses para as cidades ultramarinas, traçados, disposição e dimensionamento de lotes e edificações, conferindo autenticidade à paisagem da cidade.

No entanto, apesar de existirem diferenças entre as cidades, como a falta de edificações monumentais, de praças e de monumentos centrais ao eixo principal, provavelmente devido às características topográficas do terreno e às modestas condições econômicas da sociedade da época, observou-se que as cidades brasileiras apresentam um caráter monumental mas acanhado, se forem comparadas às implantadas na cidade de Lisboa, fato este que não desmerece a história da sociedade brasileira.

O conjunto que compõe essa área estudada caracteriza-se como um bairro, devido às suas similaridades morfológicas urbanas e arquitetônicas, facilitando, sobremaneira a elaboração de um roteiro turístico cultural, cuja permanência conta a evolução daquela sociedade.

Oportunidades não devem ser perdidas, portanto é premente a apropriação de tecnologias existentes, adaptando-as para se tornem ferramentas que possam contribuir com o desenvolvimento do turismo, como a codificação bidimensional, a qual possibilitará a disseminação de informações, não apenas para os portadores de necessidades especiais, mas também para os turistas estrangeiros que não compreendem a informações disposta nos materiais turísticos existentes.

Sugere-se que sejam realizadas outras pesquisas sobre QR Code aplicado ao turismo, para que as informações sobre a história das cidades e seu patrimônio cultural possam ser amplamente noticiadas e socializadas, e, dessa forma, possibilite aos gestores públicos e à sociedade organizada a consciência de que a preservação da memória e a identidade pode ser uma excelente oportunidade também para diversificar a fonte de renda dessas comunidades. Assim como, a publicação de materiais que esclareçam a população sobre a relevancia de perpetuar a sua historia, fortaleceram os movimentos sociais em prol desta causa. 


\section{REFERÊNCIAS}

ARANTES, N. Sistemas de gestão empresarial: conceitos permanentes na administração de empresas válidas. 2. ed. São Paulo: Atlas, 1998. 439p.

AUGUSTO-FRANÇA, J. Lisboa - historiafísica e moral. Portugal: Livros Horizonte, 2009.

BELUSSI, L. F. F. Deteç̧ão de códigos QR em imagens com enquadramento arbitrário. 2012. Dissertação (Mestrado em Ciências)- Universidade de São Paulo, São Paulo, SP, 2012.

BRASIL. Municípios de Santa Catarina aderem ao PAC Cidades Históricas. Portal Brasil, abr. 2011. Disponível em: http://www.legado.brasil.gov.br/noticias/arquivos/2011/04/06/municipios-de-santa-catarina-aderemao-pac-cidades-historicas. Acesso em: 5 maio 2012.

DENSO-WAVE. About 2D Code. Disponível em: http://www.densowave.com/qrcode/aboutqr-e.html. Acesso em: 20 mar. 2016.

EBRAHIM, Z. E-government adoption: architecture and barriers. Business Process Management Journal, v. 11, n. 5, p. 589-611, 2005. Disponível em: https://www.emerald.com/insight/content/ doi/10.1108/14637150510619902/full/html. Acesso em: 20 mar. 2016.

ENDRES, A. V.; OLIVEIRA, C.; MENEZES, D. A. Turismo no Centro histórico de João Pessoa: revitalização, planejamento e não lugar. Revista eletrônica de turismo cultural. 2o semestre, 2007.

FREITAG, B. A revitalização dos centros históricos das cidades brasileiras. Caderno CRH, Salvador, n. 38, p. 115-26, jan./jun. 2003.

HALL, C. M. Planejamento turístico: políticas, processos e relacionamentos. São Paulo: Contexto, 2001.

INTERACTIVE ADVERSTISING BUREAU - BRASIL. Do engajamento ao viewability: como a internet influenciou a medição da publicidade. IAB Basil, jul. 2016.

INSTITUTO DO PATRIMÔNIO HISTÓRICO E ARTÍSTICO NACIONAL (IPHAN). Monumenta. 2009. Disponível em: http://portal.iphan.gov.br/pagina/detalhes/398/. Acesso em: 5 maio 2012.

INSTITUTO DO PATRIMÔNIO HISTÓRICO E ARTÍSTICO NACIONAL (IPHAN). Monumentos e espaços públicos tombados - São Francisco do Sul (SC), 2010. Disponível em: http://portal.iphan.gov.br/pagina/ detalhes/1547/. Acesso em: 5 maio 2012.

KARASINSKI, L. O que significa cada quadrado de um QR Code? TEcmundo, 2013. Disponível em: http;// www.Tecmundo.com.br/q-code/37372-o-que-significa-cada-quadrado-de-um-qr-code-htm. Acesso em: 16 maio 2014.

MELGAR, M. Geração e leitura de QR Codes coloridos. 2013. 79f. Dissertação (Mestrado em Engenharia Elétrica) - Universidade de Brasília, Brasília, DF, 2013.

OKADA, S. I.; SOUZA, E. M. S. Estratégias de marketing digital na era de busca. Revista Brasileira de Marketing, São Paulo, v. 10, n. 1, p. 46-72, jan./abr. 2011.

PEREIRA, C. C. História de São Francisco do Sul. 2. ed. Florianópolis: Ed. UFSC,2004.

PREFEITURA MUNICIPAL DE SÃO FRANCISCO DO SUL. Plano de Preservação do Patrimônio Histórico de São Francisco do Sul. Arquivo do ETEC-SFS-IPHAN, 2013. 
REIS FILHO, N. G. Quadro da arquitetura no Brasil. São Paulo: Perspectiva, 1970.

ROSSI, A. A arquitetura da cidade. 2. ed. São Paulo: Martins Fontes, 1995.

SANTOS, S.; NACKE, A.; REIS, M. J. (Org.). São Francisco do Sul: muito além da viagem de Gonneville. Florianópolis: Editora da UFSC, 2004. 247p.

SASSAKI, R. K. Inclusão. Construindo uma sociedade para todos. Rio de Janeiro: WVA Editora, 1997.

VARGAS, H.; CASTILHO, A. L. H. Intervenções em Cenros Urbanos. 2. ed. São Paulo: Manole, 2009.

VAZ, L. F.. Planos e projetos de regeneração cultural: notas sobre uma tendência urbanística recente. In: SEMINÁRIO DA HISTÓRIA DA CIDADE E DO URBANISMO, 8., 2004, Niterói. Anais [...]. Rio de Janeiro: PROURB/FAU/UFRJ, 2004. [CD-ROM].

XUE, Y. C.; MORK, J.; LUNNEMANN, W. P. K.; NIELSEN, T. R. Slow and fast light in semiconductor waveguides. IOP Publishing Ltd. Semiconductor Science and Technology, 2010.

\section{Sobre os autores:}

Diva de Mello Rossini: Pós-doutora na Universidade de Lisboa (PT). Doutora em Administração e Turismo na Universidade do Vale do Itajaí (Univali). Mestre em Engenharia de produção na Universidade Federal de Santa Catarina. Graduada em Arquitetura e Urbanismo na Universidade do Vale do Itajaí. Professora dos cursos de graduação em Arquitetura e Urbanismo e Design de Interiores, da pós-graduação em Turismo e Hotelaria da Univali. E-mail: divarossini@univali.br, Orcid: http://orcid.org/0000-0002-9050-6587

Carlos Alberto Tomelin: Doutor em Administração e Turismo. Mestre em Turismo e Hotelaria. Pós-graduado em Turismo e Hotelaria. Graduado em Turismo pela Universidade do Vale do Itajaí (Univali). E-mail: tomelin@univali.br, Orcid: http://orcid.org/0000-0001-8988-4727

Luciano Torres Tricarico: Doutor em Arquitetura e Urbanismo. Mestre em Arquitetura e Urbanismo. Pós-graduado em Turismo e Hotelaria. Graduado em Arquitetura e Urbanismo pela Universidade do Vale do Itajaí (Univali). E-mail: tricarico@univali.br, Orcid: http://orcid.org/0000-0003-3307-8229

Gabriela Mocellin: Graduanda em Arquitetura e Urbanismo pela Universidade do Vale do Itajaí (Univali). E-mail: gabriela.mocellin@gmail.com, Orcid: http://orcid.org/0000-0002-6252-6011 
